\title{
Évolution de la dégradabilité dans le rumen de l'azote du ray-grass anglais au cours de la saison de pâturage
}

\author{
$\mathrm{P}$ Le Goffe, R Vérité \\ INRA, station de recherche sur la vache laitière, \\ Saint-Gilles, 35590 L'Hermitage, France
}

\begin{abstract}
Summary - Variations of protein degradability in fresh perennial rye-grass throughout the grazing season. Throughout the grazing season, nitrogen degradability of perennial rye grass is the lowest in summer and seems to be negatively correlated to lignin content of grass and to average daily temperature.
\end{abstract}

Le regroupement des résultats d'études effectuées à des périodes différentes de l'année semble indiquer que la dégradabilité de l'azote des fourrages verts appréciée par des tests simples de laboratoire (azote des parois, solubilité, dégradation enzymatique, dégradation in vitro: Moré et Simon, 1985; Hafley et al, 1987; Abdalla et al, 1988) présente une évolution saisonnière : elle diminue au printemps, passe par un minimum estival, remonte en automne et est maximale en fin d'année. Dans ce travail, nous avons voulu préciser cette évolution sur une saison complète de pâturage d'un ray-grass anglais en utilisant la méthode in sacco.

Matériel et méthodes - En 1986, au Rheu (IIle-et-Vilaine, France), 6 repousses successives de ray-grass anglais (variété Vigor) en $2^{\mathrm{e}}$ année d'exploitation ont été récoltées (les 12 mai, 2 et 27 juin, 28 juillet, 10 septembre et 15 octobre) au stade pâturage après un déprimage à la mi-avril. La fertilisation azotée est de $60 \mathrm{~kg} / \mathrm{ha}$ en fin d'hiver et la même dose après chaque coupe. Pour chacune des 6 repousses, un échantillon moyen constitué à partir de 5 blocs (micro-parcelles de $5,4 \mathrm{~m}^{2}$ ) a été congelé à $-35^{\circ} \mathrm{C}$ dès la récolte, stocké à $-15^{\circ} \mathrm{C}$, puis lyophilisé. Après broyage à la grille de $1,5 \mathrm{~mm}$, la mesure des taux de disparition de l'azote en sachets de nylon ( $t d$ ) incubés $2,4,10,24$ et $48 \mathrm{~h}$ dans le rumen et le calcul de la dégrabilité théorique de l'azote $(D T)$ avec un taux de passage des particules de $6 \% / \mathrm{h}$ ont été réalisés selon Michalet-Doreau et al (1987). Après rebroyage à la grille de $0,8 \mathrm{~mm}$, les teneurs en azote total, NDF, ADF et lignine (Van Soest, 1963), azote du NDF et de l'ADF, ont été déterminées. La lignite a été dosée après extraction préalable au détergent neutre; par contre, l'ADF a été obtenu directement.

Résultats et discussion - La teneur en azote total (fig 1) diminue notablement en juillet et septembre et est maximale en octobre. Les teneurs en NDF et ADF sont relativement stables tout au long de la saison de pâturage. La teneur en lignine évolue à l'inverse de l'azote, mais seules les valeurs extrêmes sont significativement différentes.

Le taux horaire de dégradation de l'azote est très élevé le 12 mai $(0.259)$, chute brutalement et présente un premier palier les 2 et 27 juin $(0,159$ et $0,152)$, puis un palier minimal $(0,100)$ en été et remonte faiblement le 15 octobre $(0,118)$. Le td à $48 \mathrm{~h}$ (fig 1) est élevé et peu variable $(95,9 \pm 1,3 \%)$.

La $D T$ diminue assez régulièrement du 12 mai $(88,1 \%)$ au 10 septembre $(79,8 \%)$, puis remonte le 15 octobre $(83,7 \%)$. Ses variations, quoique signi- 

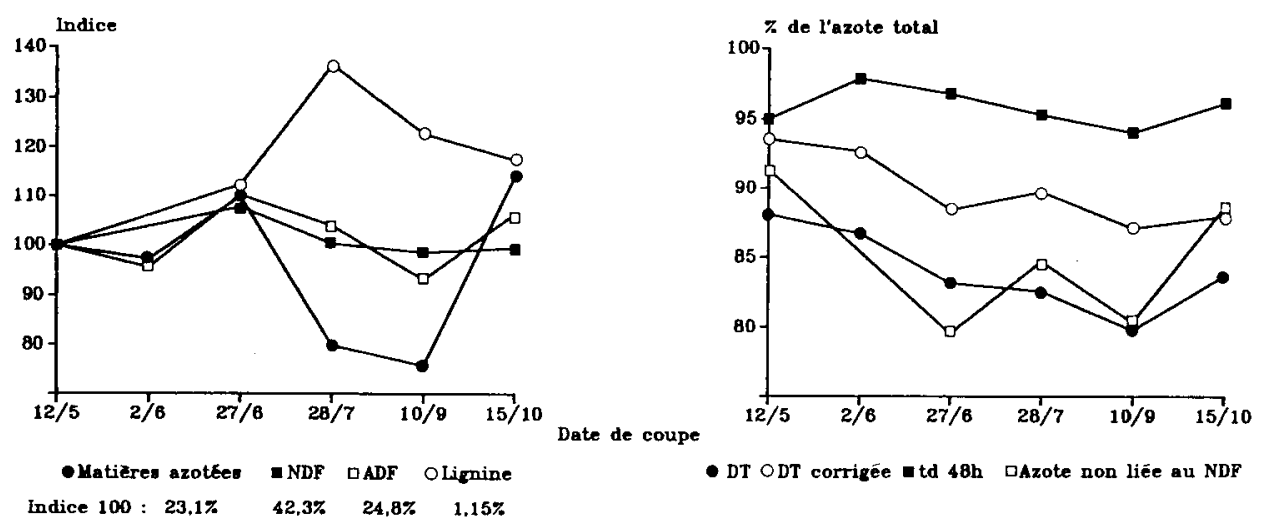

Fig 1. Évolution de la composition chimique et de la dégradabilité de l'azote du ray-grass anglais au cours de la saison de pâturage.

ficatives, sont faibles, comparées à celles des données in vitro de la bibliographie. La DT semble liée négativement à la teneur en lignine et à la température moyenne journalière, alors que les teneurs en parois sont pratiquement inchangées. Le minimum estival de $D T$ proviendrait peut-être d'une moindre accessibilité des contenus cellulaires par suite de la lignification accrue des parois, mais est également à rapprocher des plus faibles teneurs en azote total à cette époque. Par ailleurs, les valeurs de $D T$ sont voisines de celles de la proportion d'azote non liée au NDF (fig 1), mais la DT (et non le td à $48 \mathrm{~h}$ ) est mieux corrélée $\left(R^{2}=0,90\right)$ à la proportion d'azote non liée à l'ADF, qui varie pourtant très faiblement au cours de la saison $(97,9-99,1 \%)$.

Une correction a été tentée pour tenir compte de la contamination microbienne des sachets en calculant la sous-estimation de DT qu'elle entraîne à partir des teneurs en azote total et en NDF (Michalet-Doreau et Ould-Bah, 1989), bien que cette équation ait été établie sur une population mixte de fourrages verts et conservés. La remontée d'octobre constatée sur la $D T$, mais également sur les proportions d'azote non liées au NDF et à l'ADF, est annulée par la correction qui augmente la DT de 4,3 à 7,3 points selon la coupe.

La différence entre les matières azotées non dégradables théoriques et celles non disparues à $48 \mathrm{~h}$ - qui estime peut-être les matières azotées non dégradables dans le rumen mais susceptibles d'être digérées dans l'intestin - est toujours très faible, minimale le 12 mai $(1,59 \%$ de la matière sèche) et maximale les 27 juin et 15 octobre $(3,45$ et $3,27 \%$ de la MS).

Abadalla HO, Fox DG, Seaney RR (1988) $J$ Anim Sci 66, 2663-2667

Hafley J, Nipper WA, Craig WM, Adkinson RW, Achacoso AS (1987) J Dairy Sci 70, 2550-2559

Michalet-Doreau B, Ould-Bah MY (1989) $X V I$ th International Grassland Congress, Nice, France, 909-910

Michalet-Doreau $B$, Vérité $R$, Chapoutot $P$ (1987) Bull Tech CRZV INRA Theix, 69, 5-7

Moré E, Simon JC (1985) Fourrages 103, 7994

Van Soest PJ (1963) J Assoc Off Anal Chem $46,829-835$ 